\title{
Prognostic impact of large cell neuroendocrine histology in patients with pathologic stage la pulmonary non-small cell carcinoma
}

Akira Iyoda, MD, ${ }^{a}$ Kenzo Hiroshima, MD, ${ }^{b}$ Yasumitsu Moriya, MD, ${ }^{\text {a }}$ Yasuo Sekine, MD, ${ }^{a}$ Kiyoshi Shibuya, MD, ${ }^{\text {a }}$ Toshihiko lizasa, MD, ${ }^{\text {a }}$ Yukio Nakatani, MD, ${ }^{\mathrm{b}}$ and Takehiko Fujisawa, $\mathrm{MD}^{\mathrm{a}}$

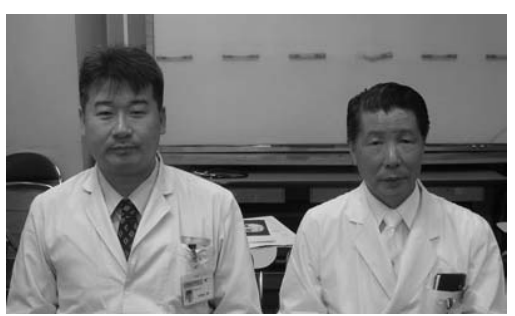

Drs Iyoda and Fujisawa (left to right)

Background: Most patients with pathologic stage Ia non-small cell lung carcinoma have a good prognosis, and adjuvant chemotherapy is currently not being used in the management of this stage of the disease. However, if significant negative prognostic factors become evident in patients with pathologic stage Ia non-small cell lung carcinoma, patients with negative prognostic factors should have adjuvant treatment after surgery.

Methods: We analyzed 335 cases of pathologic stage Ia non-small cell lung carcinoma treated between 1988 and 2003 by complete resection. The pathologic stage Ia non-small cell lung carcinomas comprised 259 adenocarcinomas, 65 squamous cell carcinomas, and 11 large cell neuroendocrine carcinomas. The prognostic impact of various clinical variables was investigated by the Cox proportional hazards multivariable regression model.

Results: Univariate analysis showed that large cell neuroendocrine carcinoma histology, old age, large tumor size, male gender, and smoking predicted poorer overall survival. Large cell neuroendocrine carcinoma had a significantly poorer prognosis than other non-small cell carcinomas. Multivariate analysis revealed that large cell neuroendocrine carcinoma was predictive of poorer overall survival $(P=.0200$, hazard ratio 2.787).

Conclusions: Large cell neuroendocrine histology has a significant adverse prognostic impact on pathologic stage Ia non-small cell carcinoma. Therefore, surgical resection alone represents insufficient treatment for large cell neuroendocrine carcinoma, even for pathologic stage Ia disease.

From the Departments of Thoracic Surgery ${ }^{\mathrm{a}}$ and Diagnostic Pathology, ${ }^{\mathrm{b}}$ Graduate School of Medicine, Chiba University, Chiba, Japan. This work was supported in part by a Grant-in-aid for Scientific Research (C)(2) 17591458 of the Japanese Ministry of Education, Culture, Sports, Science, and Technology.

Received for publication Nov 30, 2005; revisions received Feb 9, 2006; accepted for publication Feb 21, 2006.

Address for reprints: Akira Iyoda, MD, Department of Thoracic Surgery, Graduate School of Medicine, Chiba University, 1-8-1, Inohana, Chuo-ku, Chiba 260-8670, Japan (E-mail: aiyoda@faculty.chiba-u.jp).

J Thorac Cardiovasc Surg 2006;132:312-5

$0022-5223 / \$ 32.00$

Copyright (๑) 2006 by The American Association for Thoracic Surgery

doi:10.1016/j.jtcvs.2006.02.046
$\mathrm{N}$ on-small cell lung carcinoma (NSCLC) includes a wide variety of histologic types. Complete surgical resection is recognized as the most effective treatment for NSCLC. Although early clinical trials did not identify a benefit from adjuvant chemotherapy, ${ }^{1-3}$ more recent clinical trials have demonstrated a survival advantage for patients receiving adjuvant chemotherapy. ${ }^{4,5}$ Most patients with pathologic stage Ia NSCLC have a better prognosis than patients with advanced stages, and usually they do not require adjuvant chemotherapy. However, if there are categories of NSCLC with a poor prognosis even in pathologic stage Ia, patients with this class of disease should receive adjuvant therapy after complete surgical resection. In 1999 the World Health Organization ${ }^{6}$ classified large cell neuroendocrine carcinoma (LCNEC) as a variant of large cell carcinomas. Although LCNEC falls between atypical carcinoid and small cell lung carcinoma on the spectrum of clinical aggressiveness in pulmonary neuroendocrine tumors. ${ }^{7,8}$ it is not elucidated whether LCNEC is a poor prognostic factor in stage Ia NSCLC or not. In the present study, we analyzed prognostic factors including LCNEC, the new 


\section{Abbreviations and Acronyms \\ LCNEC $=$ large cell neuroendocrine carcinoma \\ NSCLC $=$ non-small cell lung carcinoma}

histologic type, in addition to several clinical variables in pathologic stage Ia NSCLC.

\section{Patients and Methods}

We retrospectively analyzed clinical data from 335 patients with primary lung carcinoma diagnosed as pathologic stage Ia NSCLC who underwent complete surgical resection with systematic lymph node dissection without adjuvant chemotherapy at Chiba University Hospital between 1988 and 2003. We excluded patients with limited surgical resection or incomplete resection. The pathologic stage Ia NSCLC consisted of 259 adenocarcinomas, 65 squamous cell carcinomas, and 11 LCNECs. Patient gender, age, smoking index, tumor size, tumor location, surgical procedure, pathologic TNM stage, and patient outcome were determined from the medical records.

\section{Statistical Analysis}

The Fisher exact test was used to compare binomial proportions. The $\chi^{2}$ test was used to assess differences in gender, tumor site, and surgical methods. The unpaired $t$ test was used to detect significant differences between patients with LCNEC and patients with other NSCLCs with respect to patient age, smoking index,

TABLE 1. Patient characteristics of pathologic stage la NSCLCs

\begin{tabular}{lc}
\hline & No. of cases (\%) \\
\hline Age (y), mean (range) & $63(36-83)$ \\
$<75$ & $301(89.9 \%)$ \\
$\geq 75$ & $34(10.1 \%)$ \\
Gender & \\
Male (\%) & $186(55.5 \%)$ \\
Female (\%) & $149(44.5 \%)$ \\
Smoking index, mean (range) & $490(0-3600)$ \\
0 & $151(45.1 \%)$ \\
$\geq 1$ & $184(54.9 \%)$ \\
Tumor size (cm) mean (range) & $2.0(0.1-3.0)$ \\
$\leq 2$ cm & $185(55.2 \%)$ \\
$>2$ cm & $150(44.8 \%)$ \\
Tumor site & \\
Right & $191(57.0 \%)$ \\
Left & $144(43.0 \%)$ \\
Histology & \\
LCNEC & $11(3.3 \%)$ \\
Other NSCLC & $324(96.7 \%)$ \\
Operation & \\
Lobectomy & $330(98.5 \%)$ \\
Bilobectomy & $5(1.5 \%)$
\end{tabular}

$\overline{L C N E C \text {, Large cell neuroendocrine carcinoma; NSCLC, non-small cell lung }}$ carcinoma.

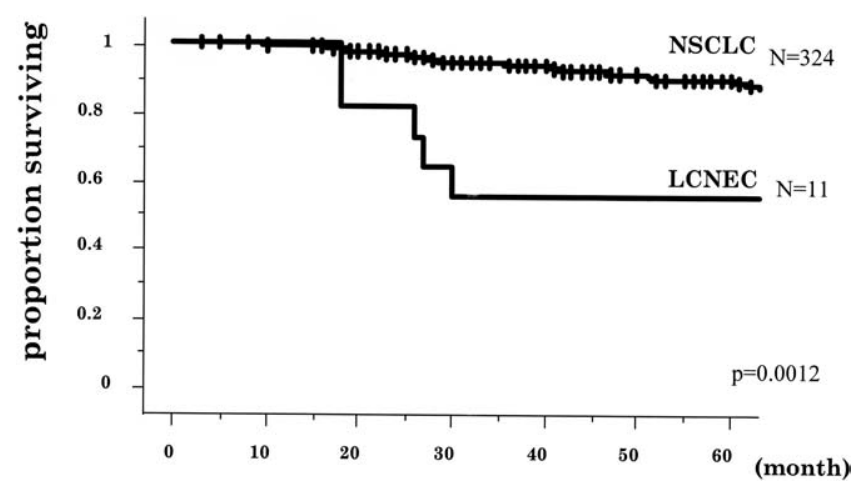

Figure 1. Analysis of overall survival indicates that patients with pathologic stage la LCNEC had a significantly poorer prognosis than patients with other types of pathologic stage la NSCLC. LCNEC, Large cell neuroendocrine carcinoma; NSCLC, non-small cell lung carcinoma.

and tumor size. Survival time, calculated from the date of surgery until the time of death, was evaluated by the Kaplan-Meier method. The curves obtained were compared with the log-rank test. The prognostic impact of the following clinical variables was investigated by the Cox proportional hazards multivariable regression model: gender (male vs female), age $(<75$ years old versus $\geq 75$ years old), smoking index $(0$ versus $\geq 1)$, histologic type (LCNEC vs other NSCLC), tumor size ( $\leq 2 \mathrm{~cm}$ vs $>2 \mathrm{~cm}$ ), and tumor site (right vs left).

\section{Results}

In this study, patients' characteristics are shown (Table 1).

The 5-year overall survival was $54.5 \%$ for patients with LCNEC and $89.3 \%$ for patients with other NSCLCs (Figure 1). Patients with LCNEC had a significantly lower overall survival than did patients with other types of NSCLC $(P=$ .0012).

Univariate analyses of survival were performed to determine predictors of overall survival in patients with patho-

TABLE 2. Univariate analyses of survival

\begin{tabular}{|c|c|c|c|}
\hline & \multicolumn{3}{|c|}{ Overall survival } \\
\hline & $P$ value & Hazard ratio & $95 \% \mathrm{Cl}$ \\
\hline \multicolumn{4}{|l|}{ Histology* } \\
\hline LCNEC & .0026 & 3.650 & $1.570-8.485$ \\
\hline Age $\dagger \geq 75$ years old & .0005 & 2.992 & $1.616-5.537$ \\
\hline Tumor size $\ddagger>2 \mathrm{~cm}$ & .0011 & 2.309 & $1.395-3.831$ \\
\hline Gender§ male & .0028 & 2.369 & $1.347-4.167$ \\
\hline Smoking index $\| \geq 1$ & .0037 & 2.237 & $1.299-3.846$ \\
\hline Site right & .0671 & 1.618 & $0.967-2.708$ \\
\hline
\end{tabular}


TABLE 3. Multivariate analyses for survivals

\begin{tabular}{lccc}
\hline & \multicolumn{3}{c}{ Overall survival } \\
\cline { 2 - 4 } & $\boldsymbol{P}$ value & Hazard ratio & $\mathbf{9 5 \%} \mathbf{~ C l}$ \\
\hline Histology* & & & \\
$\quad$ LCNEC & .0200 & 2.787 & $1.175-6.609$ \\
Age† $\geq 75$ years old & .0008 & 2.926 & $1.565-5.469$ \\
Tumor size $\neq>2 \mathrm{~cm}$ & .0080 & 1.988 & $1.196-3.311$ \\
Gender§ male & .2246 & 1.736 & $0.713-4.231$ \\
Smoking index $\| \geq 1$ & .6191 & 1.242 & $0.529-2.915$ \\
Siteף right & & & \\
\hline
\end{tabular}

$\mathrm{Cl}$, Confidence interval; $C N E C$, large cell neuroendocrine carcinoma. *Histologic type (LCNEC vs other NSCLC); $\uparrow$ Age $(<75$ years old vs $\geq 75$ years old); $\neq$ Tumor size ( $\leq 2 \mathrm{~cm}$ vs $>2 \mathrm{~cm}$ ); $\S$ Gender (male vs female); $\|$ Smoking index (0 vs $\geq 1$ ); I[Site (right vs left).

logic stage Ia NSCLC (Table 2). The following factors significantly decreased overall survival: LCNEC histologic type, age 75 years or older, tumor size greater than $2 \mathrm{~cm}$, male gender, and smoking index of 1 or more.

Multivariate analyses of survival revealed that LCNEC histologic type, tumor size greater than $2 \mathrm{~cm}$, and age 75 years or older markedly decreased overall survival (Table 3).

\section{Discussion}

The present study revealed that patients with stage Ia LCNEC had a significantly poorer prognosis than patients with other NSCLCs and that large cell neuroendocrine histology has a significant adverse prognostic impact on stage Ia NSCLC. These results suggest that surgical resection alone represents inadequate treatment for patients with LCNEC, even if it is stage Ia disease, and that patients with stage Ia LCNEC may require adjuvant treatment.

Initial studies of patients with NSCLC failed to demonstrate any survival benefit associated with adjuvant chemotherapy. ${ }^{1-3}$ However, two recent prospective randomized clinical trials have reported improved survival in patients with NSCLC receiving adjuvant chemotherapy.

In a study of oral uracil-tegafur for 2 years versus no treatment in patients with completely resected pathologic stage Ia pulmonary adenocarcinoma, Kato and associates ${ }^{4}$ reported that adjuvant chemotherapy with uracil-tegafur improved survival, especially in stage T2 disease. In a study of 3 or 4 cycles of cisplatin-based chemotherapy versus observation, Arriagada and associates ${ }^{5}$ reported that cisplatinbased adjuvant chemotherapy improved survival among patients with resected stage Ia, 2 and 3 NSCLC.

These studies thus demonstrate that patients with NSCLCs, as well as patients with small cell lung carcinomas, require adjuvant chemotherapy. Although these studies supported the routine use of adjuvant chemotherapy in patients with advanced NSCLC, the studies did not completely elucidate whether adjuvant chemotherapy would also be efficacious for patients with stage Ia NSCLC. The study by Kato and associates ${ }^{4}$ failed to identify a significant difference in survival between patients receiving adjuvant chemotherapy and control patients with stage Ia disease, although the study did find a survival benefit from adjuvant chemotherapy for patients with stage $1 \mathrm{~b}$ disease. Currently, patients with stage Ia NSCLC do not receive adjuvant chemotherapy because stage Ia disease in general has a comparatively good prognosis. However, adjuvant chemotherapy might be appropriate for a subset of patients with stage Ia NSCLC, whose tumors have a very poor prognosis.

$\mathrm{We}^{9}$ have previously reported that LCNEC appears to be a more clinically aggressive tumor than classic large cell carcinoma, LCNEC has a poorer prognosis than classic large cell carcinoma, and the identification of neuroendocrine histologic features in tumor tissue from patients diagnosed with large cell carcinoma of the lung have clinical relevance. In a second study, we ${ }^{10}$ found that adjuvant chemotherapy is effective for patients with LCNEC. On this basis, we plan in the future to routinely administer adjuvant chemotherapy to patients with LCNEC. However, this second study did not elucidate whether patients with pathologic stage Ia LCNEC require adjuvant chemotherapy.

In 1991, Travis and associates ${ }^{11}$ published the first study identifying LCNEC as a distinct type of pulmonary neuroendocrine tumor; they reported that patients with LCNEC had a survival worse than that of patients with atypical carcinoid and comparable with that of patients with small cell lung carcinoma. Since then, although some studies have reported no difference in prognosis between LCNEC and other NSCLCs, ${ }^{12}$ most reports have confirmed that LCNEC is an aggressive tumor associated with a very poor prognosis. ${ }^{9,13-18}$ Although it was not elucidated why patients with LCNEC had a very poor prognosis, we ${ }^{19}$ have previously reported that LCNEC cases exhibited an increased Ki-67 labeling index and an increased mitotic rate. The Ki-67 nuclear antigen, which is associated with cell proliferation, is detectable in the nucleus of cycling (G1, S, G2 and M-phase) cells but absent in resting (G0 phase) cells. Experimental evidence indicates that biologically active tumors express high levels of Ki-67 nuclear antigen. ${ }^{20,21}$ These findings together suggest that LCNEC has a higher level of proliferative activity than other NSCLCs, and it is associated with poor prognoses of patients with LCNEC.

Few studies have evaluated adjuvant chemotherapy for LCNEC. In 2001, we ${ }^{10}$ reported that adjuvant chemotherapy was effective for patients who had large cell carcinomas with neuroendocrine features, including LCNEC. Subsequently, other studies have concluded that adjuvant chemotherapy is necessary for patients with LCNEC. ${ }^{22,23}$ These findings provide confirmation of the results of the present study.

In this study, we revealed that even with stage Ia disease, the prognosis of patients with LCNEC was different from 
that of other NSCLC, although LCNEC is classified as a variant of NSCLC. Therefore, we should consider adjuvant treatment after complete resection for patients with LCNEC, even if it is pathologic stage Ia disease.

\section{References}

1. Feld R, Rubinstein L, Thomas PA. Adjuvant chemotherapy with cyclophosphamide, doxorubicin, and cisplatin in patients with completely resected stage 1 non-small-cell lung cancer. The Lung Cancer Study Group. J Natl Cancer Inst. 1993;85:299-306.

2. Non-small Cell Lung Cancer Collaborative Group. Chemotherapy in non-small cell lung cancer: a meta-analysis using updated data on individual patients from 52 randomised clinical trials. BMJ. 1995;311: 899-909.

3. Scagliotti GV, Fossati R, Torri V, Crino L, Giaccone G, Silvano G, et al. Adjuvant Lung Project Italy/European Organisation for Research Treatment of Cancer-Lung Cancer Cooperative Group Investigators. Randomized study of adjuvant chemotherapy for completely resected stage I, II, or IIIA non-small-cell lung cancer. J Natl Cancer Inst. 2003;95:1453-61.

4. Kato H, Ichinose Y, Ohta M, Hata E, Tsubota N, Tada H, et al. Japan Lung Cancer Research Group on Postsurgical Adjuvant Chemotherapy. A randomized trial of adjuvant chemotherapy with uracil-tegafur for adenocarcinoma of the lung. N Engl J Med. 2004;350:1713-21.

5. Arriagada R, Bergman B, Dunant A, Le Chevalier T, Pignon JP, Vansteenkiste J. Cisplatin-based adjuvant chemotherapy in patients with completely resected non-small-cell lung cancer. $N$ Engl J Med. 2004;350:351-60.

6. World Health Organization. Histological typing of lung and pleural tumours. 3rd ed. Heidelberg: Springer; 1999.

7. Travis W, Rush W, Flieder DB, Falk R, Fleming MV, Gal AA, et al. Survival analysis of 200 pulmonary neuroendocrine tumors with clarification of criteria for atypical carcinoid and its separation from typical carcinoid. Am J Surg Pathol. 1998;22:934-44.

8. Iyoda A, Hiroshima K, Baba M, Saitoh Y, Ohwada H, Fujisawa T. Pulmonary large cell carcinoma with neuroendocrine features are highgrade neuroendocrine tumors. Ann Thorac Surg. 2002;73:1049-54.

9. Iyoda A, Hiroshima K, Toyozaki T, Haga Y, Fujisawa T, Ohwada H. Clinical characterization of pulmonary large cell neuroendocrine carcinoma and large cell carcinoma with neuroendocrine morphology. Cancer. 2001;91:1992-2000.

10. Iyoda A, Hiroshima K, Toyozaki T, Haga Y, Baba M, Fujisawa T, et al. Adjuvant chemotherapy for large cell carcinoma with neuroendocrine features. Cancer. 2001;92:1108-12.
11. Travis WD, Linnoila RI, Tsokos MG, Hitchcock CL, Cutler GB Jr, Nieman L, et al. Neuroendocrine tumors of the lung with proposed criteria for large-cell neuroendocrine carcinoma. An ultrastructural, immunohistochemical, and flow cytometric study of 35 cases. Am J Surg Pathol. 1991;15:529-53.

12. Harada M, Yokose T, Yoshida J, Nishiwaki Y, Nagai K. Immunohistochemical neuroendocrine differentiation is an independent prognostic factor in surgically resected large cell carcinoma of the lung. Lung Cancer. 2002;38:177-84.

13. Takei H, Asamura H, Maeshima A, Suzuki K, Kondo H, Niki T, et al. Large cell neuroendocrine carcinoma of the lung: a clinicopathologic study of eighty-seven cases. J Thorac Cardiovasc Surg. 2002;124:285-92.

14. Zacharias J, Nicholson AG, Ladas GP, Goldstraw P. Large cell neuroendocrine carcinoma and large cell carcinomas with neuroendocrine morphology of the lung: prognosis after complete resection and systematic nodal dissection. Ann Thorac Surg. 2003;75:348-52.

15. Hage R, Seldenrijk K, de Bruin P, van Swieten H, van den Bosch J. Pulmonary large-cell neuroendocrine carcinoma (LCNEC). Eur J Cardiothorac Surg. 2003;23:457-60.

16. Ab' Saber AM, Massoni Neto LM, Bianchi CP, Ctenas BB, Parra ER, Eher EM, et al. Neuroendocrine and biologic features of primary tumors and tissue in pulmonary large cell carcinomas. Ann Thorac Surg. 2004;77:1883-90.

17. Paci M, Cavazza A, Annessi V, Putrino I, Ferrari G, De Franco S, et al. Large cell neuroendocrine carcinoma of the lung: a 10-year clinicopathologic retrospective study. Ann Thorac Surg. 2004;77:1163-7.

18. Hiroshima K, Iyoda A, Shibuya K, Haga Y, Toyozaki T, Iizasa T, et al. Genetic alterations in early-stage pulmonary large cell neuroendocrine carcinoma. Cancer. 2004;100:1190-8.

19. Iyoda A, Hiroshima K, Moriya Y, Mizobuchi T, Otsuji M, Sekine Y, et al. Pulmonary large cell neuroendocrine carcinoma demonstrates high proliferative activity. Ann Thorac Surg. 2004;77:1891-5.

20. Gerdes J, Lemke H, Baisch H, Wacker H, Schwab U, Stein H. Cell cycle analysis of a cell proliferation-associated human nuclear antigen defined by the monoclonal antibody Ki-67. J Immunol. 1984;133: 1710-5.

21. Cattoretti G, Becker MH, Key G, Duchrow M, Schluter C, Galle J, et al. Monoclonal antibodies against recombinant parts of the Ki-67 antigen (MIB-1 and 3) detect proliferating cells in microwaveprocessed formalin-fixed paraffin sections. J Pathol. 1992;168:357-63.

22. Mazieres J, Daste G, Molinier L, Berjaud J, Dahan M, Delsol M, et al. Large cell neuroendocrine carcinoma of the lung: pathological study and clinical outcome of 18 resected cases. Lung Cancer. 2002;37:287-92.

23. Kozuki T, Fujimoto N, Ueoka H, Kiura K, Fujiwara K, Shiomi K, et al. Complexity in the treatment of pulmonary large cell neuroendocrine carcinoma. J Cancer Res Clin Oncol. 2005;131:147-51.

\section{Availability of Journal back issues}

As a service to our subscribers, copies of back issues of The Journal of Thoracic and Cardiovascular Surgery for the preceding 2 years are maintained and are available for purchase from Elsevier until inventory is depleted. Please write to Elsevier, Inc., Subscription Customer Service, 6277 Sea Harbor Dr, Orlando, FL 32877 , or call $800-654-2452$ or $407-345-4000$ for information on availability of particular issues and prices. 